\title{
DO OLHAR PORTUGUÊS SOBRE MACAU: algumas representações poéticas contemporâneas
}

\author{
Catarina Nunes de Almeida ${ }^{1}$ \\ (Universidade de Lisboa)
}

\section{RESUMO}

Macau ocupa até hoje um lugar ímpar na cultura portuguesa, configurando uma entidade simultaneamente histórica, literária, política e mítica. A poesia portuguesa contemporânea tem sido persistente em recuperar os termos da complexa relação que Oriente e Ocidente foram tecendo ao longo dos séculos e essa persistência permite-nos olhar para Macau não apenas como um território geográfico, mas como um conceito com uma considerável força simbólica. Podemos, em certa medida, entender a aproximação ao imaginário macaense como nostalgia do império, como esperança do encontro não só com um passado histórico, mas também literário (através de figuras como Luís de Camões, Camilo Pessanha ou Wenceslau de Moraes, com vivências ligadas àquele território). Alguns poetas escolhidos para este estudo trabalharam por alguns anos no território (José Alberto Oliveira, Gil de Carvalho ou Fernanda Dias), outros realizaram viagens por tempo mais limitado (Sophia de Mello Breyner Andresen, em 1977, a convite do Conselho da Revolução, onde iria tomar parte das celebrações do Dia de Camões; António Manuel Couto Viana, entre 1986 e 1988, a convite do Instituto Cultural de Macau, onde colaborou enquanto docente; e Eugénio de Andrade, em 1999, numa visita breve que resultaria anos mais tarde na obra Pequeno Caderno do Oriente, publicada em 2004). A evocação dum conjunto fixo de lugares (por exemplo, a Gruta de Camões ou o Jardim Lou Lim Ieoc), continuamente retomados pela escrita, resultou na cristalização duma cartografia literária associada a Macau, cujo mapeamento e a interpretação este estudo propõe. PALAVRAS-CHAVE: Macau; Memória Cultural; Poesia Portuguesa Contemporânea; Orientalismo Português. 


\section{Macau e o Oriente no imaginário português}

Com a viagem do Gama até à Índia, o Oriente torna-se num dos tópicos mais significativos do imaginário português. Goa e Macau, particularmente, funcionariam desde cedo como espelhos míticos do Império, configurando a simbólica imagem dum paraíso perdido na memória cultural do país. Porém, diferentemente da passagem por Goa, na qual muitos autores portugueses depositam as esperanças dum encontro com um éden longínquo, com uma realidade que estará para além deles próprios - o que faz de Goa um espaço inseparável da sua dimensão exótica -, na passagem por Macau parece ter existido sempre uma procura distinta: o desejo de encontro consigo mesmos, o vislumbre duma essência comum refletida, ainda que fosse do outro lado do espelho. Macau seria aquele espaço que, fora da metrópole, melhor conservaria a imagem da metrópole - um padrão vivo, no dizer de Camilo Pessanha - o rosto que lá longe melhor se pareceria com o do próprio Portugal.

Essa leitura apaixonada que transforma Macau numa imagem especular da metrópole portuguesa era já o ponto de chegada do texto de Camilo Pessanha, «Macau e a Gruta de Camões», publicado no jornal $A$ Pátria em 1924. Senão recordemos os seguintes excertos:

Macau é o mais remoto padrão da estupenda actividade portuguesa no Oriente nesses tempos gloriosos. Note-se que digo padrão, padrão vivo: não digo relíquia. [...]

[...] Assim é Macau a única terra do ultramar português em que as estações são as mesmas da Metrópole e sincrónicas com estas. [...] Quem estas linhas escreve teve, por várias vezes (há quantos anos isso vai!), deambulando pelo passeio da Solidão a ilusão [...] de caminhar ao longo de uma certa colina da Beira Alta, muito familiar à sua adolescência.

[...] Veio esta divagação a propósito de dizer que ainda é Macau a única terra de todo o ultramar português em que se pode ter até certo ponto a ilusão de se estar em Portugal, essencial ao exercício por portugueses da sua especial actividade imaginativa... (PESSANHA, 1993, p. 121-122)

Porém, Macau representa também - e para o mesmo autor - uma imagem em miniatura da vasta e inacessível China. Se uma face de Macau propicia a nostalgia das origens e o prazenteiro exercício de identificação 
entre o cá e o lá, a outra face revela-se densa, complexa e incompreensível, uma encruzilhada de diferenças que se concretiza numa realidade estranha ou mesmo intransponível (e para isto bastará reler alguns parágrafos da «Introdução a Um Estudo sobre a Civilização Chinesa», que Pessanha escreve em Macau no ano de 1912).

Alguns poetas escolhidos para este estudo trabalharam por alguns anos no território (caso de José Alberto Oliveira, Gil de Carvalho e Fernanda Dias), outros realizaram viagens por tempo mais limitado (Sophia de Mello Breyner Andresen, em 1977, a convite do Conselho da Revolução, onde iria tomar parte das celebrações do Dia de Camões; António Manuel Couto Viana, entre 1986 e 1988, a convite do Instituto Cultural de Macau, onde colaborou enquanto docente; e Eugénio de Andrade, em 1999, numa visita breve que resultaria anos mais tarde na obra Pequeno Caderno do Oriente, publicada em 2004). A evocação dum conjunto fixo de lugares (a própria Gruta de Camões ou o Jardim Lou Lim Ieoc), continuamente retomados pela escrita, resultou na cristalização duma cartografia literária (e também cinematográfica, embora a excluamos da nossa leitura) associada a Macau, cujo mapeamento e interpretação este estudo propõe.

Concentremo-nos, desde logo, nesses dois espaços invocados recorrentemente pela escrita, os quais constituem interessantes contributos para uma cartografia poética de Macau - a Gruta de Camões e o Jardim de Lou Lim Ieoc. De certa forma, eles concretizam a coexistência das duas faces de Macau a que fizemos alusão: uma que reflete as marcas de um Portugal ainda presente, ainda reconhecível, e a outra que remete para toda uma linguagem cultural codificada, esquiva e por vezes de difícil tradução.

\section{As Faces de Macau}

Entre os poetas que destacamos neste estudo, encontramos pelo menos três textos cujo título aponta diretamente para essa espécie de santuário de matriz lendária, no qual se presta um culto à figura de Camões, a qual, desde há séculos, se instituiu ter vivido em Macau, onde inclusivamente teria estado preso e onde teria "desempenhado as apagadas funções de provedor dos defuntos e ausentes" (PESSANHA, 1993, p. 119). Referimo-nos, em concreto, ao poema de Sophia de Mello Breyner Andresen, «Gruta de Camões» (que surge logo no segundo livro da autora, Dia do Mar, de 1947 - ou seja, trinta anos antes da viagem a Macau que daria origem à obra Navegações); ao poema de António Manuel Couto Viana, 
«Na Gruta de Camões» (da obra No Oriente do Oriente, de 1987); e ao breve texto de Eugénio de Andrade, «Em Defesa de Camões», publicado no Pequeno Caderno do Oriente (2002).

Ora, num ensaio intitulado precisamente «Grutas de Camões: Poesia Portuguesa e Orientalismo a partir da Crítica de Camilo Pessanha», publicado em 2014, Duarte Drumond Braga também esclarece que a incidência sobre este topos vem "ao encontro da relação complexa que o orientalismo português mantém com a sua própria memória literária, muito presente na evocação da figura de Camões" (BRAGA, 2014, p. 53). Não há viajante que não parta em busca de uma reminiscência e é essa busca que norteia o próprio itinerário. Procura-se satisfazer, sempre que possível, uma memória construída mentalmente, um legado de imagens concedido pelo tempo e pela literatura. Mas esta Gruta reveste-se de um outro simbolismo: o culto de Camões "é também o da Pátria", como afirma Pessanha (1993, p. 123) e, como agrada a Eugénio de Andrade, a sua poesia permite ainda hoje "perpetuar a imagem do português no Oriente" (2002, p. 25). Assim, seguindo uma operação metonímica algo complexa, estar na Gruta é como estar na pátria portuguesa, mas do outro lado do mar.

Poemas dos primeiros livros de Sophia, entre os quais a «Gruta de Camões», colocam-nos perante uma espécie de nostalgia da epopeia, uma epopeia interior, numa época de repressão política em que se aspirava já a um movimento coletivo de renovação do país. Assim, pelo poder da memória, a viagem real e concreta suscita outras, que fazem parte de um património coletivo. Naturalmente, existem ecos intertextuais com a épica de Camões, com quem Sophia partilha o desejo de cantar a gesta de um povo que encontrou no mar o seu destino. Esse espírito aventureiro também explica as conotações positivas associadas à ideia de deriva. $\mathrm{O}$ Oriente figura como símbolo maior da História de Portugal, mas a sua evocação não é apenas um modo de enaltecer e elogiar o passado, é sobretudo uma apologia de um novo tempo e de um novo mundo. Em Sophia, como acontece com outros autores contemporâneos, a representação do Oriente é desencadeada, pelo menos numa primeira fase, por uma revisitação do percurso biográfico de Camões, que muito se terá cruzado com aquele espaço - daí a primeira referência explícita a esse cenário mítico, construído a partir da imaginação, surgir no referido poema "Gruta de Camões» (ANDRESEN, 2010, p. 109), do livro Dia do Mar: "Dentro de mim sobe a imagem dessa gruta / Cujo silêncio ainda escuta / Os teus gestos e os teus passos". 
$\mathrm{O}$ apego da literatura portuguesa contemporânea à figura de Camões (e também de Fernão Mendes Pinto) para reproduzir a imagem do poeta errante ou peregrinante de quinhentos, aproxima os portugueses, como explica Eduardo Lourenço,

da autêntica verdade da nossa aventura terminada. Esta conversão do nosso imaginário mítico começa a ter a sua tradução presente numa atenção, numa memória, igualmente desmistificadoras do nosso próximo passado, no qual o antigo espaço português, como palco de dramas que foram e são nossos, é lugar da nossa obrigatória definição. (2014, p. 268, itálico do autor)

Com efeito, apesar de no texto de Couto Viana prevalecer ainda uma alusão a Camões como referência ecuménica da aventura marítima portuguesa, sem nunca transpor a enunciação canónica e lírica da figura (ou dessa "Gruta nem gruta" (VIANA, 2004a, p. 23)) onde se teria demorado), o texto «Em Defesa de Camões», de Eugénio de Andrade, questiona já a ficcionalidade em torno destes tropos.

Sustentando a sua defesa de Camões a partir da própria dúvida de que algum dia o mesmo ali tenha estado, Eugénio opera a desmistificação a que alude Lourenço, ou seja, uma fuga bem "mais realista que a da epopeia irreversível" (2014, p. 268). Leia-se:

Vim, como toda a gente, para ver a gruta, ou lá o que é, onde, segundo tradição que penetrou no sangue desta terra, Luís Vaz de Camões se refugiava para escrever no silêncio, ou embalar a sua melancolia. É possível: a colina é bonita, e do alto os olhos facilmente encontravam nas águas da baía a lembrança doutras mais distantes; e, na verdade, Luís Vaz andou aos trambolhões por tanto lado que não é difícil ter vindo parar a Macau. (ANDRADE, 2002, p. 25)

Ora, esta desconstrução do mito vem ao encontro da argumentação do próprio Pessanha, que defendia que o simbolismo da Gruta e a sua situação geográfica em Macau deviam manter-se acima dos factos que pudessem confirmar (ou não) a passagem efetiva do poeta d'Os Lusíadas por ali.

Sobre isto, Camilo Pessanha escreve o seguinte:

Tem-se debatido desde há anos a questão de se Camões residiu ou não em Macau [...]. A polémica há-de decerto renascer mais animada algum dia; e provável é que o problema venha a decidir-se finalmente pela negativa.

[...] E, pois, que Macau, não só pelas suas condições climáticas mas 
também como mais remoto padrão de acção portuguesa na Ásia, é o palmo de terra mais próprio para essa evocação se fazer, natural é que [...] seja em Macau o santuário nacional - pan-lusitano - consagrado ao génio do poeta, e que a Macau a biografia deste particularmente se refira.

[H]á-de ser verdade intuitiva, superior a todas as investigações históricas, que o maior génio da raça lusitana sofreu, amou, meditou, em Macau [...]. (1993, p. 119, 123)

Este posicionamento de Pessanha, aberto à verdade intuitiva, torna-se ainda mais interessante quanto mais presente tivermos a ideia de que, décadas mais tarde, à sua própria figura serão atribuídas funções igualmente representativas ou simbólicas. Camilo Pessanha será também ele revisitado, quer na poesia quer na prosa, por um conjunto heterogéneo de "leitor[es]-admirador[es] que não defende[m] a verdade dos factos, antes sublinha[m] a proeminência artística de quem os fomentou", ou seja, que sustentam essa mesma verdade intuitiva, como explica Serafina Martins no breve ensaio «Camilo Pessanha: o poeta e a sua personagem» (2010, p. 97). Neste texto, a autora refere o seguinte:

Por simples coincidência ou por motivos que a falta de informação não permite determinar, tanto a sua vida como a sua poesia caíram numa espécie de roda viva na qual ele teve pouca mão, o que contribuiu para criar um mistério que nenhum esforço talvez possa resolver.

[...] Ironicamente, é do seu lugar de exílio que nascem histórias sobre o poeta, histórias cuja menoridade não impediu a sua verdadeira institucionalização. A imagem que se construiu do poeta tem directamente a ver com o mistério antes referido, com aquilo que ele não disse e com o espaço deixado para que outros viessem falar de si.

[...] No entanto, as ditas "fantasias" têm um interesse que não é desprezível, apesar das muitas reservas que suscitam; na verdade, tiveram uma atenção especial por parte de leitores que podemos considerar especiais também: escritores que se interessaram por Camilo Pessanha, não numa perspectiva crítica, mas para uma recriação literária de um homem cuja vida teve como acontecimento proeminente ter escrito poemas maravilhosos [...]. (2010, p. 95-96)

Tomemos por exemplo, mais uma vez, o Pequeno Caderno do Oriente, de Eugénio de Andrade: além da poesia e dos textos seguirem a forma e os conceitos inspirados pelo pensamento estético do Extremo 
Oriente - a escrita concisa, límpida e nominal é visitada por vários tropos correspondentes àquela tradição, como o bambu, as pedras, as rãs - esta é uma das obras que manifesta também uma homenagem à fonte indireta desse fascínio, o próprio Camilo Pessanha (desde logo a partir do texto com que inaugura a obra, "Camilo Pessanha, o Mestre» (ANDRADE, 2002, p. 7-11)).

Ora, Camilo Pessanha parece constituir a referência central duma assimilação estética da China feita por diversos poetas portugueses contemporâneos. A sua homenagem cruza-se com uma homenagem mais ampla a todo o universo oriental - os reiterados elogios que encontramos nos textos (que incluem ainda o seu companheiro Wenceslau de Moraes) operam também por metonímia: resgatar a figura de Pessanha é uma forma de aproximação àquele espaço e, por outro lado, resgatar aquele espaço é uma forma de destacar Pessanha.

Esta tendência encontra expressão em outros poetas da geração de Eugénio de Andrade, seguindo por vezes linhas poéticas bem distintas da sua - disso é exemplo o próprio A. M. Couto Viana, que lhe dedica dois poemas na composição «4 Poetas em Macau», incluída em No Oriente do Oriente (2004a, p. 49-50). Assim, se evocar a Gruta de Camões é evocar Camões e evocar Camões é evocar a pátria, então evocar Pessanha (e também Wenceslau) - sobretudo pelas suas notáveis tentativas de interpretação da China e do Japão, traduzidas em vários textos - evocá-los, enfim, será sempre evocar Macau (ou o Oriente) enquanto Outro (isto é, não tanto a face portuguesa e imperial, mas sobretudo a face estrangeira, mais propriamente oriental, do mesmo Oriente).

Ponderemos então sobre essa outra face de Macau, que nos parece estar sintetizada num espaço discreto conhecido como Jardim Lou Lim Ieoc. Trata-se de um jardim de estilo chinês, cuja construção se iniciou no século XIX, com vista a integrar a residência dum influente mercador chinês local. A partir dos anos 70, o jardim foi aberto ao público, tornando-se numa conhecida atração turística de Macau. Ora, se nos reportarmos aos poemas que evocam o Jardim Lou Lim Ieoc, damos conta da imersão num espaço que é retomado sobretudo enquanto cenário exótico, cujos variadíssimos detalhes os poetas procuram fixar através da escrita. Porém, existem sempre detalhes que o estrangeiro não domina e que o mantêm cativo dum jogo de proximidade e distância.

Referimo-nos, concretamente, aos poemas de A.M. Couto Viana («No Jardim de Lou Lim Ieoc» (2004a, p. 31-32)), de Eugénio de Andra- 
de («Jardim de Lou Lim Ieoc» (2002, p. 15)), de Fernanda Dias («Lou Lim Ieoc» (1992, p. 23)) e de José Alberto Oliveira («No Jardim de Lou Lim Ieoc, Lendo Oblomov» (2013, p. 165-166)). As imagens adequam-se às descrições canónicas dum jardim tradicional chinês. Todos estes poemas que evocam o Jardim dão conta duma simbiose de referências, o que caracteriza geralmente as descrições literárias de Macau, porém, concedem aqui uma enorme prevalência aos tropos e aos símbolos que preenchem a tradição lírica chinesa, por serem pertences genuínos das suas paisagens e da sua cosmologia: apontamos sobretudo para elementos particulares da natureza, como o bambu, o lótus, a jade, o pavilhão chinês, ou mesmo elementos mitológicos, como o dragão.

Este lugar consubstancia um ponto de fusão, um vaso comunicante entre os dois mundos, Ocidente e Oriente. Os sujeitos líricos revelam-se disponíveis e desejosos de assimilar o híbrido de imagens e de componentes materiais dessa mundividência tão distinta (José Alberto Oliveira fala-nos de «uma pataca por um assento / de pedra e três quartos de hora», fala-nos do «gengibre da inspiração» (2013, p. 165)), e quanto mais os sujeitos se vão deixando atravessar por eles, mais crentes ficam de terem alcançando a tradução possível para uma linguagem que permanecerá sempre estrangeira e enigmática.

Mas quem diz um jardim, diz a gastronomia, o vestuário, a escrita, as artes, os templos, os espaços públicos, as hierarquias sociais, enfim, tudo o que cabe numa sociedade sem par com a europeia e que, a partir do século XIX, exigiria do Ocidente um contínuo esforço de interpretação. Essa face outra de Macau, sempre presente mas inapreensível, a impor sempre uma certa estranheza às muitas tentativas de decifração do desconhecido, encontra-se particularmente plasmada na obra de António Manuel Couto Viana (sobretudo, através da linha poética ensaiada pelo autor em No Oriente do Oriente, de 1987, e Até ao Longínquo China Navegou..., de 1991).

$\mathrm{O}$ «Breve Roteiro Lírico de Macau» constitui, desde logo, uma introdução digna dum longo panegírico, marcado pela positividade do olhar. Porém, o elogio do Oriente proposto por A. M. Couto Viana apresenta-se como um elogio pátrio, saudosista: apontar a grandeza dos lugares é, de certo modo, revisitar uma cartografia histórica, uma pertença coletiva. Fernando Pinto do Amaral, no prefácio aos seus 60 Anos de Poesia, propõe precisamente essa ideia: 
Articulando-se com este imaginário associado a um certo conceito da infância, a escrita de António Manuel Couto Viana tem vindo a manifestar igualmente, ao longo do tempo, um acentuado fascínio por todo um conjunto de mitos e símbolos heróicos, de índole geralmente patriótica, que vemos desfilar pelos seus versos e lhes conferem a dimensão épica $[\ldots]$ - traduzida, acima de tudo, por uma exaltação nacionalista de Portugal e da História Portuguesa durante os oito séculos de existência do país. Nesse sentido, uma poesia como a de A. M. Couto Viana pode considerar-se legítima herdeira de uma corrente política monárquica e profundamente conservadora, apta a celebrar jubilosamente as glórias do nosso passado colectivo e procurando manter viva a chama de um "destino imperial" português, desse ideal restauracionista que permanece [...]. (2004, p. 16)

A topografia que serve de mote aos poemas nunca se afasta desse legado ancestral, desse simbolismo épico recuperado sobretudo nos poemas do «Livro I», de No Oriente do Oriente, onde a exaltação nacionalista será inspirada por lugares históricos - disso é exemplo o seguinte excerto de «Nas Portas do Cerco»:

Estas Portas do Cerco, de corpo espesso e rude,

São um velho soldado:

O uniforme gasto e medalhado

Cobre-lhe o coração de grandeza e virtude.

$[\ldots]$

Se não pode hastear, mais altivos, mais alto

Que a bandeira da China erguida em frente,

Os castelos e quinas que o sagraram presente

E o sangraram de glória a cada assalto

[...] (VIANA, 2004a, p. 24)

Em No Oriente do Oriente, a poemas como este juntam-se, entretanto, outros registos de viagem que oscilam entre um certo fervor etnocêntrico - "Com desgosto, olho a mesa, onde a toalha / Se enodoa de casca de gordura / Que o chinês, quando come, ao seu redor espalha: / E sonho o fresco linho e a cambraia pura" (Idem, p. 34) - e o intenso deslumbre pela paisagem - "Escreve-te, daqui, o coração / Tudo o que não te disse frente a frente, / Sufocado de amor, como um adolescente, / Ó rio Lijang!" (Idem, p. 58). Mais tarde, em Até ao Longínquo China Navegou..., a dicotomia mantém-se e o patriotismo saudosista atinge a sua máxima 
expressão: "Rezo-te, Portugal, missionário do Oriente, / Que sagrou esta terra e aqui descansa / Num momento de paz que o Céu consente. / E depois continua. E ascende! E alcança!"' (VIANA, 2004b, p. 195).

Em Couto Viana, os textos ainda dão sinais dessa busca de matriz romântica da própria identidade na alteridade. O "eu" ora se identifica com os "outros", ora se distingue deles, colocando-se sempre a si mesmo (ou às suas raízes culturais) como o tipo de referência, o que faz com que o trabalho de escrita, de uma maneira geral, não seja posto ao serviço duma aproximação às diferenças e revele ainda uma certa incapacidade de outrar o outro.

Entretanto, ao revermos com alguma atenção o corpus de poetas portugueses de passagem por Macau, é possível encontrarmos um ou outro exemplo dum olhar pós-colonial mais clínico e cru, por vezes marcado pela ironia, como o que encontramos no poema de Gil de Carvalho «Traço e Cor», onde nos oferece uma breve caricatura daqueles que aguardavam com expectativa a passagem administrativa do território para a República Popular da China: "O Português, da Administração, veste a rigor / E sossega a concubina. / Voyeurs em Macau, à espera que o século / passe a empena, ultramarina" (1998, p. 217).

\section{Conclusões}

As ideias que atrás propusemos mostram que alguns poetas portugueses contemporâneos, quando escrevem a partir da experiência macaense, parecem procurar ainda duas dimensões do Oriente que ecoam desde o Romantismo: o passado histórico e a experiência do exótico. No que respeita ao passado histórico, como vimos, um processo interessante através do qual Macau volta a figurar na poesia portuguesa decorre da cristalização, e consequente reinvenção, de obras e de figuras como as de Luís de Camões, Camilo Pessanha e Wenceslau de Moraes. A evocação de Macau retoma, em inúmeros textos, o discurso da memória cultural portuguesa e a poesia contemporânea assegura, sobretudo através da evocação destas figuras, uma continuidade simbólica, tomando parte num enredo onde a todo o momento os sujeitos revelam os seus predecessores, recuperando-os enquanto personagens (aspeto muito visível também no romance português contemporâneo, onde as biografias de Camões e de Pessanha têm sido reconstruídas em diversas obras, cujas histórias se desenrolam, naturalmente, em Macau). 
A emergência da memória como conceito teórico nas sociedades ocidentais produziu um foco extraordinário nas diferentes crises do século XX, entre elas, os processos de descolonização, que se desencadearam um pouco por todo o mundo. Esse olhar crítico, que atravessará a literatura e quase todas as formas criativas de expressão, deu origem à busca inconsciente por um conjunto de heranças culturais, que não só permitem validar uma permanência de séculos nos territórios ultramarinos, como reconstroem e legitimam uma identidade coletiva inerente a esses espaços, seja ela nacional ou transnacional.

Para alguns dos autores que aqui destacámos, a escrita sobre o Oriente parece corresponder ainda, mesmo que inconscientemente, ao exercício de autoprojeção coletiva que absorve a literatura portuguesa desde o século XIX. Escrever sobre Macau é - não só, mas sobretudo - escrever sobre Portugal. Alguns destes textos apresentam-se, por isso mesmo, como derivações duma linhagem orientalista, embora, como é óbvio, a imagem do Oriente já não seja construída à luz do colonialismo ou do nacionalismo político (que, por muito tempo, terão sido responsáveis pela instrumentalização do próprio conceito de Orientalismo). $\mathrm{O}$ que subjaz aos textos contemporâneos, que se centram na representação de Macau, parece-nos ser uma espécie de impulso ético, comprometido com a prevalência da memória história e com uma revisão contínua da identidade portuguesa. Isso explica o foco nas grandes figuras, como Camões ou Pessanha, operando ainda, nos nossos dias, como símbolos dum Portugal que partiu para fora de si mesmo.

\section{THE PORTUGUESE LOOK ON MACAO: some contemporary poetic representations}

\section{ABSTRACT}

Macao has ever been a unique place in Portuguese culture with a deep reach of literary, historical, political and mythological influence. Portuguese contemporary poetry has persistently addressed this complex relationship between the East and the West over the centuries. This persistence allows us to view Macao not only as a geographical territory, but also as a concept with a 
considerable symbolic force. To some extent, this idea of Macao underpins a certain nostalgia of the Portuguese empire, in which the historic past interlaces the literary heritage (e.g. Luís de Camões, Camilo Pessanha or Wenceslau of Moraes were all closely linked to Macao). Some poets chosen for this study lived and worked for many years in the territory (e.g. José Alberto Oliveira, Gil de Carvalho ou Fernanda Dias). Others experienced an interaction with Macao that was more limited in time (Sophia de Mello Andresen in 1977; António Manuel Couto Viana, between 1986 and 1988; Eugénio de Andrade in 1999). The recurrent evocation of some landmarks (e.g. Camões Grotto or Lou Lim leoc Garden) by different authors resulted in the definition of a literary landscape unique to Macao. This study aims at mapping and interpreting this unique landscape.

KEYWORDS: Macao; Cultural memory; Portuguese contemporary poetry; Portuguese orientalism.

\section{REFERÊNCIAS}

ANDRADE, Eugénio de. Pequeno Caderno do Oriente. Macau: Instituto Camões / Instituto Cultural da R.A.E. / Instituto Português do Oriente, 2002.

ANDRESEN, Sophia de Mello Breyner. Dia do Mar. In: Obra Poética. Alfragide: Caminho, 2010. p. 73-163.

AMARAL, Fernando Pinto do. Um Sino no Deserto. In: VIANA, António Manuel Couto. 60 Anos de Poesia. Lisboa: Imprensa Nacional - Casa da Moeda, 2004. V.1, p. 7-20.

BRAGA, Duarte Drumond. Grutas de Camões: Poesia Portuguesa e Orientalismo a partir da Crítica de Camilo Pessanha. eLyra, Porto, n. 4, p. 45-55, 2014. Disponível em: < http://www.elyra.org/index.php/elyra/article/viewFile/57/59>. Acesso em: 15 abr. 2018.

DIAS, Fernanda. Horas de Papel (Poemas para Macau). Macau: Livros do Oriente / IPOR, 1992.

LOURENÇO, Eduardo. Da ficção do império ao império da ficção. In:

Do Colonialismo como Nosso Impensado. Lisboa: Gradiva, 2014. p. 256-269.

MARTINS, Serafina. Camilo Pessanha: o poeta e a sua personagem. In: LABO- 
RINHO, Ana Paula; PINTO, Marta Pacheco (Org.). Macau na Escrita, Escritas de Macau. V.N. Famalicão: Húmus, 2010. p. 93-106.

OLIVEIRA, José Alberto. Mais Tarde. In: ALMEIDA, Catarina Nunes de; BRAGA, Duarte Drumond (Org.). Nau-Sombra - Os orientes da poesia portuguesa do século XX. Lisboa: Vega, 2013. p. 165-166.

PESSANHA, Camilo. Macau e a Gruta de Camões. In: China. Estudos e Traduções. 2. ed. Lisboa: Vega, 1993. p. 119-124.

VIANA, António Manuel Couto. No Oriente do Oriente. In: 60 Anos de

Poesia. Lisboa: Imprensa Nacional - Casa da Moeda, 2004a. V.2, p. 9-59. . Até ao Longínquo China Navegou.... In: 60 Anos de Poesia.

Lisboa: Imprensa Nacional - Casa da Moeda, 2004b. V.2. p. 157-210.

NOTA

1 Este trabalho é financiado por fundos nacionais através da FCT - Fundação para a Ciência e a Tecnologia, I.P., no âmbito do projeto de pós-doutoramento SFRH/ BPD/84592/2012.

Recebido em: 28/06/2018

Aceito em: 18/01/2019 